\title{
STUDENTS' OPPINION ON THEIR ROLE IN PUBLIC HEALTH AND THE PREVENTION OF RISK FACTORS
}

\author{
Hr. Milcheva, K. Mollova, P. Teneva \\ Medical College, Trakia University, Stara Zagora, Bulgaria
}

\begin{abstract}
The adopted National Concept "Health Objectives 2014-2020" sets out the main public health priorities that are aimed at improving the health of the population, including vulnerable groups exposed to risk factors. The most recent publications of our authors (V. Borisov, T. Vodenicharov, 2017) address key issues in public health and offer innovative approaches and strategies to actively involve the responsible institutions in the implementation of modern health policy. They determine the risk factor as "such a sign or element of a person's living environment (climate, season, residence, diet, stress, harmful habits, etc.) that creates a probable chance of one or another disease occurring. The scientific literature describes the following behavioral risk factors: Smoking; Alcoholism; Drug addictions; Motor inactivation; Irrational eating; Stress; Risky sexual behavior; Drug dependence. Under Bulgarian law, health professionals have the right to work independently or in a team and to carry out the preventive activities, the regulations for which are published by Ordinance 1 of 2011.

The aim of this report is to present the opinion of modern health professionals (rehabilitation students and medical laboratory assistants) about their competences and autonomous role in public health and on the prevention of behavioral risk factors.

Material and methods: survey studies, analysis of educational and normative documentation, review of scientific literature.

Results and Discussion: Analyzes of the conducted studies show that future healthcare professionals are aware of behavioral risk factors and have competence to carry out a range of activities (on prescription, team and self) focused on curative, prophylactic, promotional and rehabilitation care and events for the patient, regulated by Legislative 1 Professional Activities from 2011.

A high proportion of those surveyed determined stress as the most hazardous daily risk factor. Researchers offer different strategies with more than 2 stress-management activities. More than half of them are clearly aware of their role in public health.

Conclusions and conclusion. Healthcare professionals are a major resource for the implementation of preventive activities in the field of public health. In the current conditions, the emergence of integrated professional fields requires improvement of health promotion competencies in areas such as health tourism, management, care for the elderly and others.
\end{abstract}

Key words: health, risk factors, competencies, prevention, role

The adopted National Concept "Health Objectives 2014-2020" defines the main public health priorities that are aimed at improving the health of the population, including vulnerable groups exposed to risk factors; ensuring a better quality of life and reducing health inequalities through a comprehensive, fair, sustainable and high-quality healthcare system (1).

The concept has been developed on the basis of the current World Health Organization (WHO) strategies for Europe. Leading in this respect is The European Commission's "Health for Growth" program, whose aims are to implement policies and programs in outpatient care and to create conditions for effective partnership between health institutions and the non-governmental sector $(2,3)$.

The concept of Health Promotion defined in the Ottawa Charter for Health Promotion is: The process of creating opportunities / chances / through self-regulating health behaviors to improve their own health. Immediate aim of Health Promotion is to form a healthy lifestyle, with ultimate aim - improving health by avoiding or minimizing the impact of health risk factors. Borisov describes, "the risk factor is such a sign or element of a person's living environment (climate, season, place of residence, diet, stress, harmful habits, etc.) that creates a conditional probability for one or another disease." (4). The scientific literature 
describes the following behavioral risk factors: Smoking; Alcoholism; Drug addictions; Motor inactivation; Irrational eating; Stress; Risky sexual behavior; Drug dependence.

Tsv.Tsvetanov, 2016, reviews Strategies for Health Improvement, as he emphasizes on the importance of both the Behavioral strategies focused on behavioral risk factors and lifestyle, and the Social strategies focused on social and environmental factors of the living environment (5).

The most recent publications (Borisov, Ts. Vodenicharov, 2017) review key issues in public health and offer innovative approaches and strategies for actively involving the responsible institutions in the implementation of modern health policy (6). Shared responsibility for all health-related institutions is needed, as well as the responsibility of the individual for his / her own health by preventing behavioral risk factors and forming a healthy lifestyle. For this purpose, it is important to use the potential of health professionals to carry out health-promotion activities among the population and their responsibilities for personal and public health. They have a key role to play in implementing health promotion.

In training students at the Medical High Schools it is extremely important to form their own style of thinking, spiritual development and the pursuit of improvement rather than just mastering professional knowledge. This idea is shared by Ts. Vodenicharov and V. Borisov, 2017, which point out that "the learning process ... should be a stimulating factor for the trainees to go the path of spiritual development." Health professionals are often perceived by society as a role model in the society, including in regard of the lifestyle. Therefore, by adopting knowledge and activities to preserve and strengthen their own health, they would be very useful to people that they educate and motivate for a healthy lifestyle. For this purpose, creative thinking is needed to find the most appropriate solutions in medical practice. The creative style of thinking is characterized by three essential features: associative, innovative and nondogmatic thinking (6).

Andonova 2017 focuses on another important moment in the training of medical professionals - the formation of communicative competence. "The specifics of their work require them to be able to listen and communicate, react quickly and adequately in an emergency, not show personal emotions and fears, create a sense of trust, objectively evaluate the situation and develop and maintain their own emotionality" (7).

This requires a reorientation of the teacher's pedagogical approach from classical to interactive teaching methods to turn students into active participants in the learning process. Regarding the health-promotion competencies and activities in the field of public health, the individual work of the students on a predetermined topic is being applied more and more recently. The preparation of presentations and course works on the Health Promotion and the inclusion of students in events and projects related to prophylactic, prevention and promotion of health, contribute to the formation of their own creative style of thinking in each student. As Ts. Vodenicharov and V. Borisov, 2017, emphasize "a significant factor in forming a creative thinking style in the student is the demonstration of trust by the teacher, ... because the student is not a passive object of influence but an active thinking subject who must be treated with respect and trust by the teacher (6).

In order to be trusted by patients, health professionals should be competent and able to carry out professional activities responsibly in their three dimensions: in a team with a physician, by appointment, and on their own. A wider public awareness of the WHO policies, European Commission and national health promotion policies and strategies is needed. Under Bulgarian law, health professionals have the right to work independently or in a team and to carry out preventive activities, the regulations of which are published in Ordinance 1 of 2011 (8).

The purpose of this report is to present the views of modern healthcare professionals (rehabilitation therapists and medical laboratory assistants) about their competences, on the prevention of behavioral risk factors and their autonomous role in the field of healthcare and public health.

Material and Methods: An anonymous group survey was conducted by a total of 75 students, third-year students of the specialties Rehabilitation therapist and Medical laboratory assistant at the Medical College, Tr. U, as well as analysis of educational and regulatory documentation, review of scientific literature on key issues related to public health and the prevention of behavioral risk factors.

Results and Discussion: More than half of the surveyed students know the World Health Organization (WHO) definition of health, namely "Health is a state of complete physical 
/ biological / psychological and social wellbeing, not just absence of disease or disability." They also become acquainted with the Health promotion Concept during the study of the subject.

Health promotion is an interdisciplinary activity and involves the participation of professionals from different professional fields for its implementation (9).
MILCHEVA HR., et al. In this sense, half of the respondents $(51 \%)$ stated that responsibility for Health promotion should be borne by everyone - the state, the municipalities, every person, the family. A small proportion $(36 \%)$ think that responsibility is only for the individual, and about $13 \%$ have indicated more than one answer. (Figure 1)

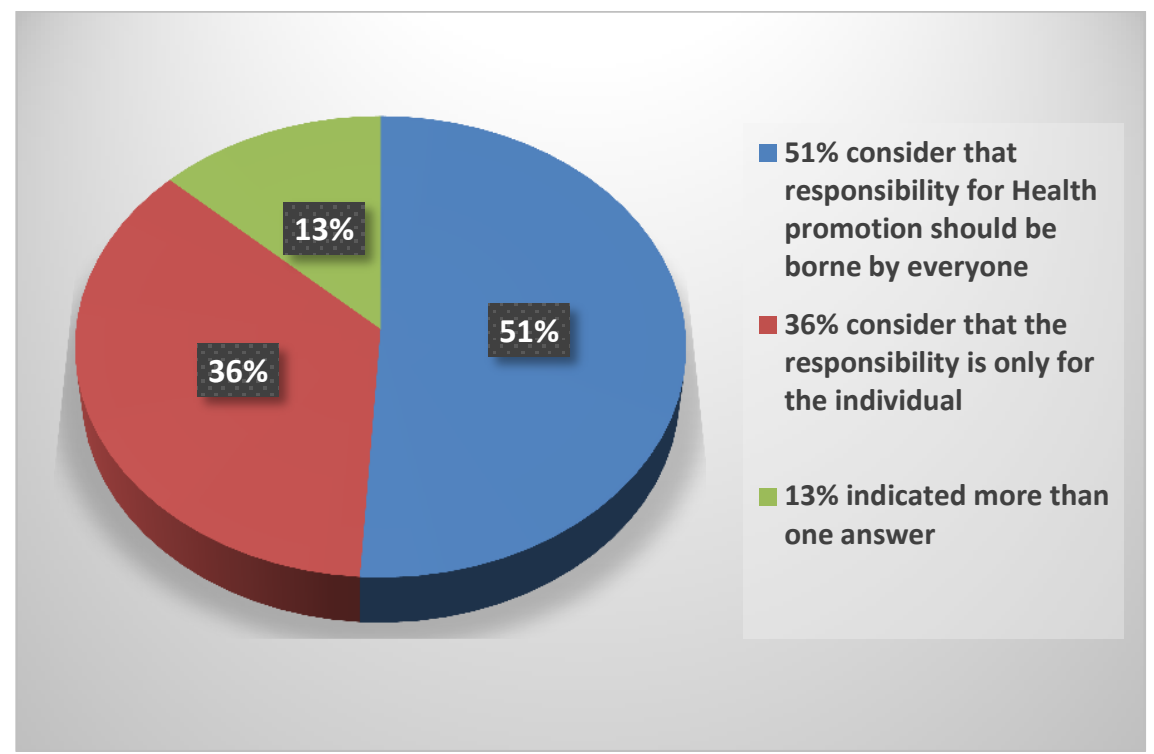

Figure 1. Responsibilities for health promoting of the nation, according to the surveyed

Regarding the knowledge of the risk factors for health, the answers range from 1 to 7 risk factors. The larger groups $(35 \%)$ indicated 3 risk factors, $27 \%$ indicated 4 risk factors, $16 \%$ indicated 2 risk factors, $12 \%$ indicated 1 risk factor. About $10 \%$ indicated more than 5 risk factors, as only $4 \%$ of the surveyed indicated the most ( 7 risk factors). It is noteworthy that most responses refer to behavioral risk factors. (Figure 2)

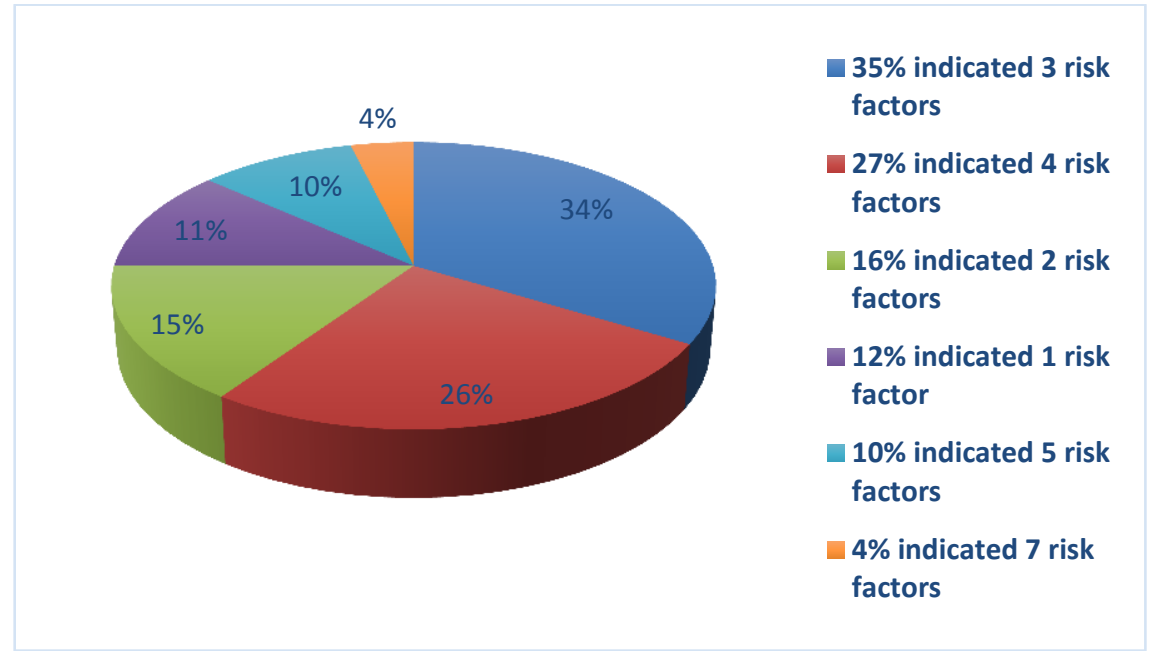

Figure 2. Knowledge of behavioral risk factors of the surveyed

A high proportion of those surveyed determined the stress as the most hazardous daily risk factor. To overcome stress, healthcare professionals apply different coping strategies depending on the stress situation. Such studies indicate that "the implementation of one or another way to overcome difficulties is an editorial choice based on specific personality characteristics and the specific situation in different areas" (10)

In regard to how they deal with stress in everyday life, responses are also different. Almost equal are those who have attitude towards positive thinking and relaxing (29\%) and those who cannot cope (28\%). There is a group of those who have indicated more than 
one action to deal with stress (21\%), those with more than 2 actions (17\%) and those with more than 3 actions (4\%). Most often students point
MILCHEVA HR., et al. out hobbies, listening to music, walking, relaxing. (Figure 3)

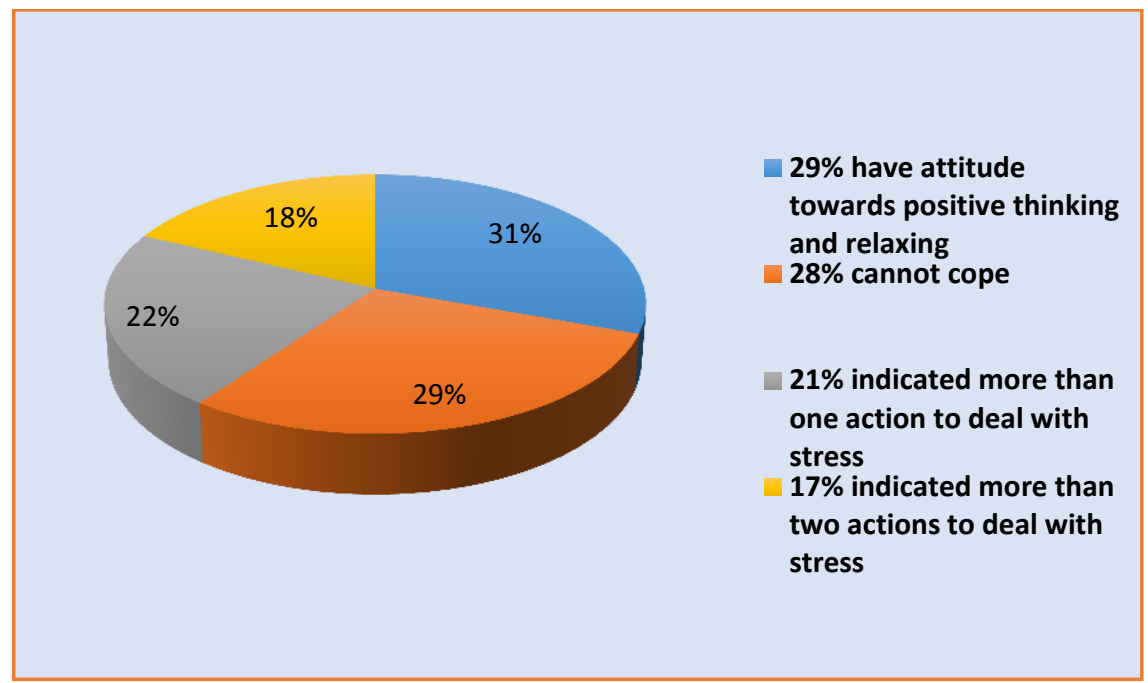

Figure 3. Strategies to deal with "stress", according to the surveyed

Regarding whether they are aware of their role as health care professionals, more than half $(52 \%)$ are aware of what is expected of them, the remaining (48\%) still cannot determine it and have not responded. This indicates that broader public awareness is needed about health promotion activities that people could expect from healthcare professionals because they are still not perceived by society as professionals having a direct impact on public health. Informing health managers about the regulations in Ordinance 1 of 2011 is needed, so that people can trust healthcare professionals with regard to their autonomous function of conducting health promotion activities. (Figure 4)

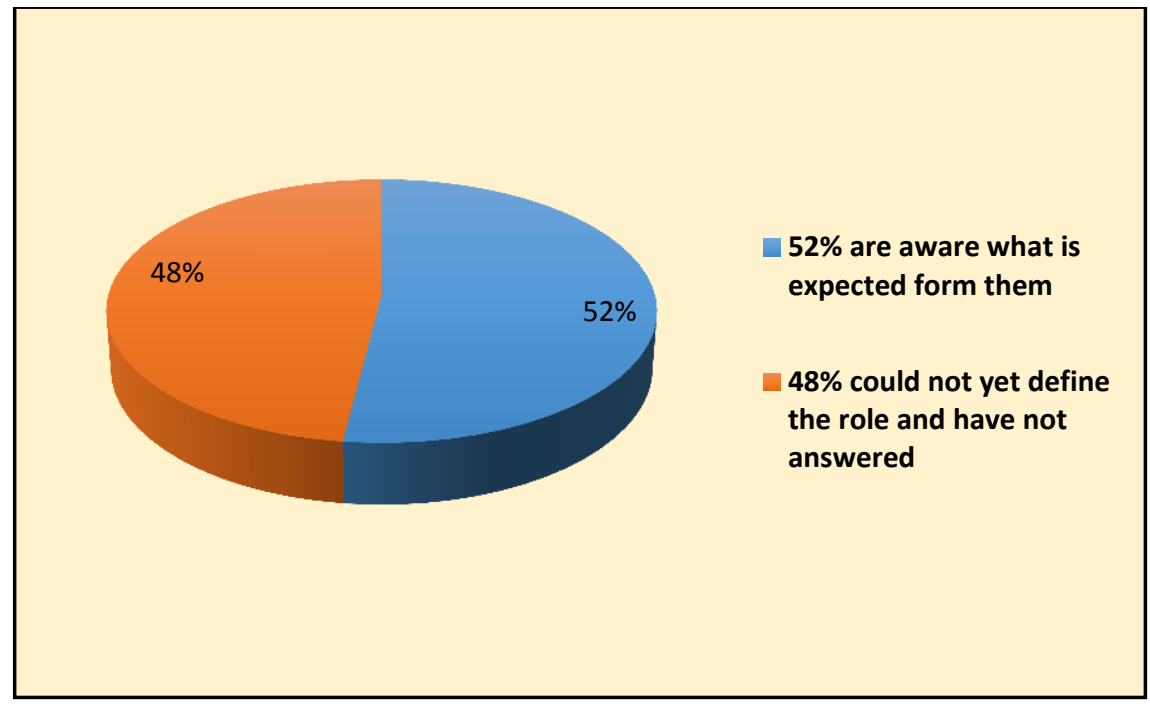

Figure 4. Role of health professionals in the field of public health

A high proportion of students $(62 \%)$ reported that they have already participated in scientific, experimental and project activities related to public health. Teachers and students from the medical college have been actively involved in the development and implementation of health promotion projects for children and the elderly in recent years. Together with Bulgarian association of professionals in health care (BAPHC) a postgraduate training is conducted, including issues related to prevention and prophylactic (of HIV, AIDS and hepatitis), etc. All students interested in the subject were given the opportunity to attend the lecture. (Figure 5) 


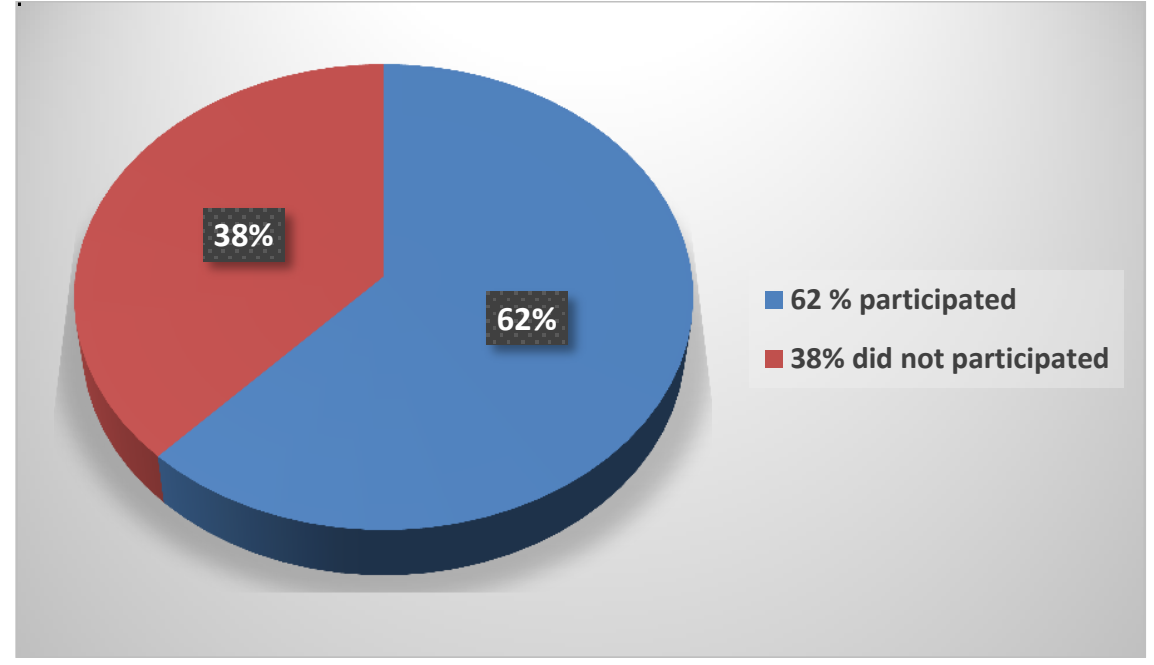

Figure 5. Participation of students in activities and projects related to health promotion

A high relative share of students $(95 \%)$ is willing to participate in the future in various events related to health promotion in the future. The results obtained give a reason for even more active work and training in this direction. All this is an indicator of a serious need for health- educational, educational and motivational activities among health care students. Exercising the professional activities related to health promotion will contribute to improving health and awareness of the need for their implementation. (Figure 6)

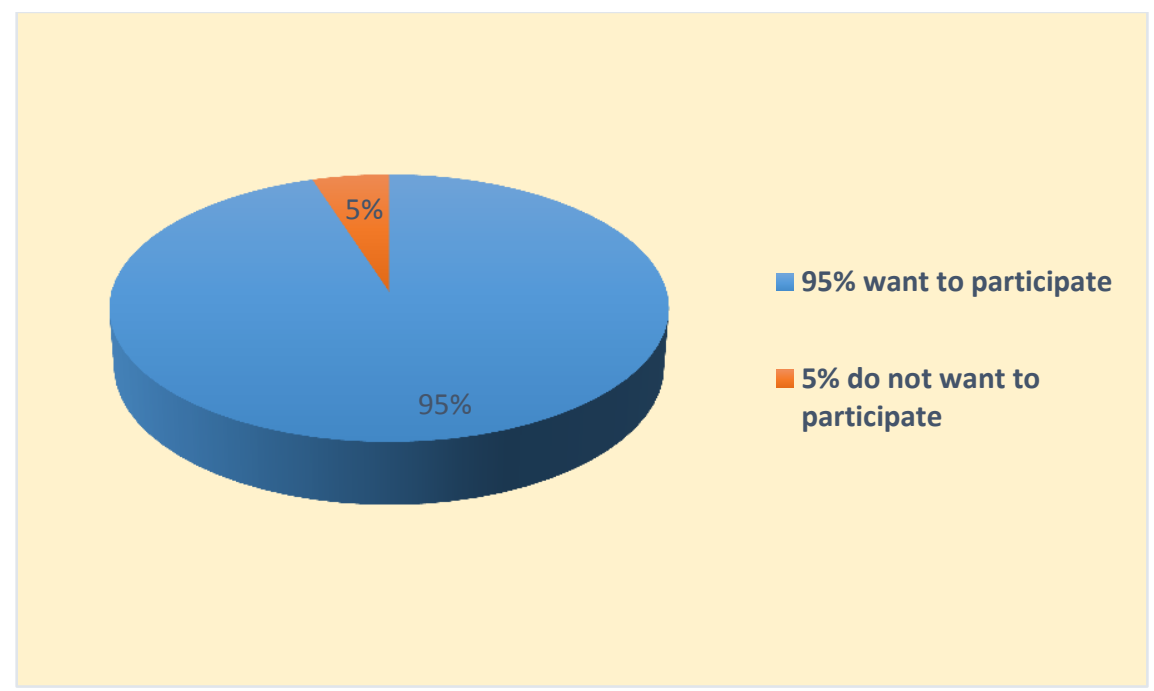

Figure 6. Students wish to participate in health promotion events

\section{Inferences:}

1. Students, the future health professionals, are aware of behavioral risk factors and have competence to carry out a range of activities (on prescription, in a team and alone), focusing on healing, prophylactic, promotional and rehabilitation care and activities for the patient. 2. A high proportion of those surveyed define stress as the most stressful risk factor and offer different strategies with more than two stress coping activities.

3. A high relative share of students $(95 \%)$ is willing to participate in the future in various events related to health promotion.

4. More than half of the researchers are clearly aware of their role in public health, but a broad public awareness of health promotion activities is needed which they might expect from health professionals and using their full potential.

\section{CONCLUSION}

Healthcare professionals are a key resource for implementing preventive activities in the public health sphere. Their potential is still not fully utilized because of the lack of knowledge of regulations by health managers and public attitudes. In the modern conditions, the emergence of new integrated professional fields necessitates the improvement of health promotion competencies in areas such as health tourism, management, care for children and the elderly, etc. and the active involvement of health professionals in health promotion activities. 


\section{REFERENCES}

1. National Health Strategy 2020, Council of Ministers of Republic of Bulgaria, 21.09.2013

2. European Health Strategy http://ec.europa.eu/europe2020/index_en.ht $\mathrm{m}$

3. European Program"Health for growth" in the field of health for the period 2014-2020. European Commission Brussels, COM (2011) 709, final 2011/0339 (COD), 9.11.2011

4. Borisov C. Health Promotion, ARSO, Sofia 1998

5. Tsvetanov Tsv., Ph.D, Thesis on "Health Promotion and Prevention of Diseases in Primary Care" for the award of Doctor's Degree Program, Sofia, 2016

6. Vodenicharov, T., B. Borisov. The Phenomenon of Public Health in the
MILCHEVA HR., et al. Changing World, GorexPress , p.284, 286, 2017

7. Andonova, A., The importance of effective communication in medical practice, Academic journal Management and Education, VOL XIII (5), p. 9-12

8. Ordinance № $1 /$ 08.02. 2011 on the professional activities which medical nurses, midwives, associated medical specialists and healthy assistants may do by appointment or alone, Ministry of Health, SG Issue 15/18.02.2011

9. Georgieva St., Study of the Conditions, Competencies and Partnership for Health Promotion in Schools in the Pleven Region, Thesis for the award of Doctor's Degree Program, Pleven

10.Dragomirova M., Study of the Most Common Strategies for Stress Management in Healthcare Professionals, Health and Science, Issue1, p. 7-10, 2018 